\title{
Perceptions of Business Skill Development by Graduates of the University of Michigan Dental School
}

\author{
Michael Barber, D.D.S.; Robert Wiesen, D.D.S.; Sara Arnold, D.D.S.; Russell S. Taichman, \\ D.M.D., D.M.Sc.; Linda Susan Taichman, R.D.H., M.P.H., Ph.D.
}

Abstract: Many graduating dentists leave dental school feeling that they are not prepared to start and run a dental practice. The aim of this pilot study was to explore the knowledge and perceptions dental graduates have in the area of practice management. A twenty-item survey was mailed in the fall of 2008 to nearly half of the University of Michigan dental school alumni who had graduated between the years of 1997 and 2007. Respondents were asked about their demographics, practice characteristics, and perceptions of knowledge/experience regarding practice management skills at the present time as well as at graduation. Data were analyzed using descriptive and inferential statistics. The majority of respondents were general practitioners (84 percent) aged thirty to thirty-nine practicing between six and ten years with practice incomes reported to be greater than $\$ 300,000$ per year (79 percent). Most dentists reported being either an owner or co-owner of the practice ( 57 percent), and 33 percent reported being an associate in the practice. Upon graduation, 7 percent of the respondents felt that they had a strong knowledge of accounting or human resource issues; this perception increased to 47 percent at the present time. Similarly, less than 6 percent of respondents felt they understood issues pertaining to dental insurance upon graduation; this perception increased to 68 percent after having spent time in the workforce. In contrast to the large increase in knowledge/experience in business aspects of dentistry that had accrued since graduation, most alumni reported only a 7 percent increase in their knowledge of the legal aspects of dental practice. Results from this study indicate that interventions are needed to increase graduating dentists' knowledge of practice management and close the gap between their knowledge and its application in real life. The majority of alumni believed there is a need to improve the curriculum focused on these aspects of dental practice.

\begin{abstract}
At the time this study was conducted, Dr. Barber was a dental student, University of Michigan, and in the Scholars Program in Dental Leadership; Dr. Wiesen was a dental student, University of Michigan, and in the Scholars Program in Dental Leadership; and Dr. Arnold was a dental student, University of Michigan, and in the Scholars Program in Dental Leadership; Dr. Russell Taichman is Professor, Department of Periodontics and Oral Medicine, School of Dentistry, University of Michigan; and Dr. Linda Susan Taichman is Assistant Professor, Department of Periodontics and Oral Medicine, School of Dentistry, University of Michigan. Direct correspondence and requests for reprints to Dr. Linda Susan Taichman, Department of Periodontics and Oral Medicine, School of Dentistry, University of Michigan, 1011 North University Ave., Ann Arbor, MI 48109-1078; 734-764-5502; hipolite@umich.edu.
\end{abstract}

Keywords: practice management, dental education, dentists, business aspects of dentistry, dental practice

Submitted for publication 7/12/10; accepted 11/10/10

$\mathrm{D}$ entists are trained to diagnose, treat, and prevent diseases and conditions relating to the teeth and the oral cavity. In the United States and Canada, the majority of dentists complete four years of dental education beyond college. During these four years most dental students participate in courses focused on the basic biological sciences (e.g., anatomy, microbiology) and clinical sciences (e.g., preclinical restorative, prosthodontics). While clinical experience often begins early in the dental school setting, the first two years of dental school primarily focus on the science of dentistry, while the last two years typically focus educational time on supervised clinical settings. The need to rapidly gain competence in the scientific underpinnings of the profession and to acquire clinical skills leaves little time for additional coursework. With increasing frequency, new graduates look for opportunities to work with an established dentist or enter into advanced education programs to further develop and hone their clinical skills.

Once graduates enter the workforce, the majority of practicing dentists become small business owners in solo or group practices. As such, dentists direct and supervise a number of other health care professionals including other dentists, dental hygien- 
ists, dental assistants, laboratory technicians, and receptionists. New dentists also find themselves focusing on a number of administrative tasks including bookkeeping, financial forecasting, retirement planning, human resources, navigating insurance plans, buying equipment, maintaining inventories, and advertising. Each of these areas requires skill sets that must be mastered to lead and manage a successful business enterprise. Excellent communication skills, self-discipline, and sound business backgrounds are essential for success in a private practice as well. Development of these skills is frequently not a primary focus in the dental school setting. ${ }^{1-3}$

The traditional curricular path in which business and management skills are emphasized in dental schools is in practice management courses. These skills are also learned in the clinical setting, ethics and professionalism curriculum, and behavioral sciences courses. Once a student leaves the academic environment, the business side of dentistry is often learned through mentoring by an established practitioner, on the job training, study groups, peer mentoring, and continuing education courses. Yet this approach may be dated for new graduates facing the challenges of today's complex and dynamic economic environments.

Despite increasing trends towards participation in advanced technical training, graduates often report that they are confident in their ability to practice dentistry ${ }^{4-6}$ However, graduating dentists also report that they are not prepared to lead and manage the business of a practice. ${ }^{7-9}$ In spite of this, few new graduates enroll in formal business training. ${ }^{10}$ The reasons for these divergent behaviors and beliefs are unclear, but suggest that an exploration on how to better prepare students to enter the world in which they will spend their professional lives would be of strategic value. The aim of this pilot study was to explore how alumni of the University of Michigan School of Dentistry feel about their practice management and business education. For this purpose, a survey was sent to the school's graduates from the preceding ten years (1997-2007) to determine their views and perceptions of their practice management skills at graduation and at the present time.

\section{Materials and Methods}

A complete list of dental alumni from years 1997 to 2007 was obtained from the University of Michigan School of Dentistry alumni office. A personal letter, questionnaire, and self-addressed, stamped envelope were mailed in fall 2008 to a random sample of nearly half $(n=500)$ of the school's alumni from the specified years. The surveys were anonymous, and no follow-up surveys were sent. Subjects were asked to return the surveys within a three-month period using the enclosed envelope. Permission to contact subjects for this study was obtained from the University of Michigan Health and Behavior Sciences Institutional Review Board.

The twenty-item questionnaire was designed and piloted with dental faculty members at the University of Michigan. Closed-ended questions were used to gather information from alumni regarding their age, years in practice, position within dental practice, number of years at this practice, personal income, number of operatories within the practice, number of employees, number and position of employees, income and practice characteristics, and whether the respondent was in a specialty practice. Practice management knowledge/experience information was elicited through a series of questions. Respondents were asked whether they felt prepared in practice management upon graduation as well as the length of time it took from graduation to feel comfortable with practice management activities. Several questions specifically asked the respondents to rate their perceptions of knowledge/experience regarding various practice management activities at the present time vs. at graduation on a 1-5 Likert-type scale, with 5 being the most experienced/knowledgeable. Topics surveyed included legal issues, accounting, human resources, purchasing, overhead, associateships, case acceptance, motivational tools, marketing, insurance, and retirement planning. In addition, two open-ended questions were used to evaluate respondents' feeling of preparedness in practice management upon graduation and provide an opportunity for feedback for curriculum development. Another open-ended question asked respondents to recommend any speakers, books, continuing education (CE) courses, etc. that would benefit students in learning practice management.

Of the 500 surveys mailed, twelve were returned by the postal service for insufficient or expired forwarding addresses. Of the remaining 488 surveys, 133 were complete and usable. The response rate was 27 percent (133/500) returned completed surveys.

In preparation for analyses, data were entered into an Excel spreadsheet. A random 10 percent of entries were rechecked for data-entry errors. Data were then imported from Excel into SAS (SAS Insti- 
tute, Cary, NC), a statistical software package for the analyses. Responses were summarized descriptively for each question and expressed as percent frequency. The responses collected for the questions in which the respondents rated their perceived knowledge/ experience of practice management activities at graduation and at the present time on a scale of 1-5 were dichotomized into "low knowledge experience" (1 to 3 ) and "high knowledge/experience" (4 and 5). To determine relationships between a respondent's practice management knowledge/experience and demographic and practice characteristics, chi-square and Fisher exact test analyses were used. In addition, for each respondent the difference of perception of preparedness from graduation to the present was compared using a one sample t-test. All reported $\mathrm{P}$-values are two-tailed, and P-values less than 0.05 were considered statistically significant.

\section{Results}

Table 1 presents the personal and practice characteristics of the 1997-2007 University of Michigan School of Dentistry alumni respondents. The majority of respondents reported that they were general practitioners ( 84 percent) between the ages of thirty and thirty-nine who had practiced between zero and ten years. Most reported being either an owner or co-owner of the practice (57 percent), and 33 percent reported being an associate in the practice. Nearly 50 percent of the respondents reported a personal income between $\$ 101,000$ and $\$ 200,000$ per year, while almost 79 percent reported that their practice income was greater than $\$ 300,000$ per year. Slightly over 41 percent of the respondents indicated that they worked in a practice that had seven or more operatories, while 48 percent stated that their workplace had three to five operatories. The majority (64 percent) worked in practices in which seven or more employees were the norm.

Figure 1 presents the respondents' perception of feeling prepared in practice management upon graduation from dental school. An overwhelming number ( 85 percent) reported that they had felt uncomfortable with their practice management education at the time of graduation. After spending time in the workforce, significant changes in their confidence or knowledge were reported in many aspects of practice management (Figure 2). For example, regardless of graduation year, less than 6 percent of the respondents felt they understood issues pertaining to dental insurance
Table 1. Demographics and practice characteristics of respondents to the survey $(n=133)$

\begin{tabular}{lcc} 
Variable & Number & Percenta \\
\hline Age & & \\
$20-29$ & 20 & $15.5 \%$ \\
$30-39$ & 98 & $76.0 \%$ \\
$40-49$ & 9 & $7.0 \%$ \\
$50-59$ & 2 & $1.6 \%$ \\
$\quad$ 60 & 0 & 0 \\
Years in Practice & & \\
$0-5$ & 60 & $45.1 \%$ \\
$6-10$ & 65 & $48.9 \%$ \\
11-15 & 8 & $6.0 \%$ \\
Work Status & & \\
Associate & 44 & $33.3 \%$ \\
Owner & 51 & $38.6 \%$ \\
Co-owner & 24 & $18.2 \%$ \\
Faculty & 12 & $9.1 \%$ \\
Other & 1 & $0.8 \%$
\end{tabular}

Years at Practice

$\begin{array}{lll}0-2 & 39 & 29.5 \% \\ 3-4 & 47 & 35.6 \% \\ 5-6 & 23 & 17.4 \% \\ 7-8 & 10 & 7.6 \% \\ 9-10 & 13 & 9.8 \%\end{array}$

Number of Operatories

$\begin{array}{lcc}2 & 3 & 2.3 \% \\ 3 & 22 & 16.9 \% \\ 4 & 14 & 10.8 \% \\ 5 & 26 & 20.0 \% \\ 6 & 11 & 8.5 \% \\ 7 \text { or more } & 54 & 41.5 \%\end{array}$

$\begin{array}{lcc}\text { Employees } & & \\ 0-2 & 5 & 3.8 \% \\ 3 \text { or } 4 & 27 & 20.8 \% \\ 5 \text { or } 6 & 15 & 11.5 \% \\ 7 \text { or more } & 83 & 63.8 \%\end{array}$

\section{Practice Income}

$\begin{array}{lll}\leq \$ 100 K & 4 & 3.6 \%\end{array}$

$\begin{array}{lll}\$ 101-200 K & 10 & 8.9 \%\end{array}$

$\begin{array}{lll}\$ 201-300 K & 10 & 8.9 \%\end{array}$

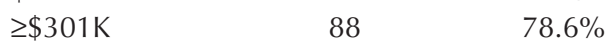

Personal Income

$\begin{array}{lll}\leq \$ 100 \mathrm{~K} & 25 & 19.4 \%\end{array}$

$\begin{array}{lll}\$ 101-200 K & 64 & 49.6 \%\end{array}$

$\begin{array}{lll}\$ 201-300 K & 21 & 16.3 \%\end{array}$

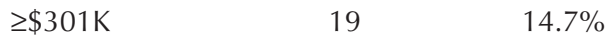

$\begin{array}{lcc}\text { Specialist } & & \\ \text { Yes } & 21 & 15.9 \% \\ \text { No } & 111 & 84.1 \%\end{array}$

Note: Percentages may not total $100 \%$ because of rounding. The number of responses to individual items varied. 


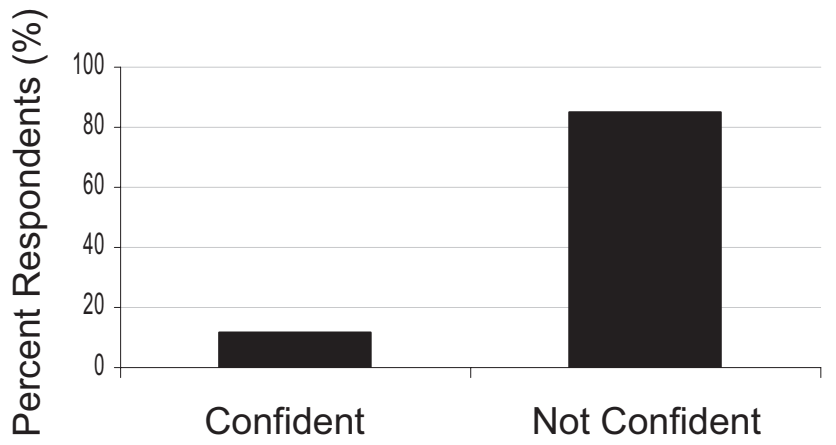

Figure 1. Percentage of respondents who reported they were confident in their preparedness in practice management knowledge upon graduation

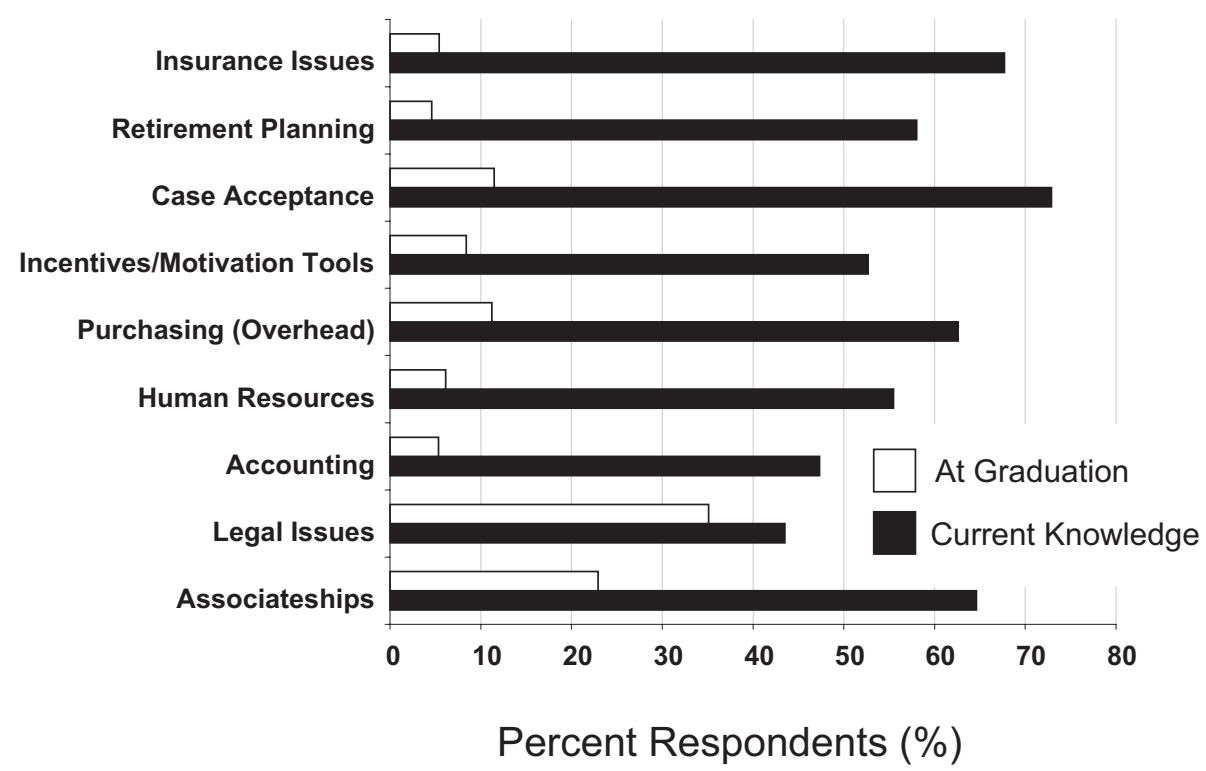

Figure 2. Percentage of respondents who reported they were confident in their knowledge in practice management areas at graduation and currently

at the time of graduation. This increased to 68 percent of respondents who reported feeling knowledgeable at the time of the survey. Only 6 percent of the respondents reported that they felt prepared at graduation in aspects pertaining to retirement planning, but 57 percent reported being prepared in this area at the time of the survey. Likewise, a similar trend was seen in respondents who self-reported knowledge in case acceptance and the use of incentives and motivation tools, purchasing, and managing overhead issues in running a practice. Approximately 47 percent of the respondents felt that they had a strong knowledge of accounting issues at the time of the survey, which had increased from 6 percent at the time of graduation. In sharp contrast to the significant gains in knowledge/ experience in business aspects of dentistry, under- 
standing the legal aspects of a dental practice had increased only 7 percent over time.

Table 2 shows the association between the respondents' perception of knowledge/experiences in practice management topics and the number of years they had practiced. Compared to respondents who had practiced five years or less, respondents who had practiced six years or more had a significantly higher knowledge of practice management topics with the exception of case presentation and legal issues. Table 3 shows the correlations among respon- dents who indicated being prepared at graduation with the level of knowledge/experience in specific practice management topics at the time of the survey using chi-square analysis. The respondents indicating preparedness at graduation in practice management skills were consistently more likely to indicate a high knowledge/experience of all practice management topics at present. Respondents who indicated a feeling of being prepared in practice management topics at graduation were significantly more likely than those indicating not feeling prepared to have a

Table 2. Association between respondents' perception of knowledge/experience in practice management topics and number of years practicing $(n=133)$, by number and percentage of total respondents to each question by category of years in practice

\begin{tabular}{|c|c|c|c|c|c|}
\hline \multirow[b]{2}{*}{ Topic } & \multicolumn{2}{|c|}{5 Years or Less } & \multicolumn{2}{|c|}{6 Years or More } & \multirow[b]{2}{*}{ P-Value } \\
\hline & Number & Percentage & Number & Percentage & \\
\hline \multicolumn{6}{|l|}{ Purchasing } \\
\hline High knowledge & 25 & $42.4 \%$ & 51 & $78.5 \%$ & \\
\hline Low knowledge & 34 & $57.6 \%$ & 14 & $21.5 \%$ & 0.001 \\
\hline \multicolumn{6}{|l|}{ Case Presentation } \\
\hline High knowledge & 39 & $67.2 \%$ & 49 & $76.6 \%$ & \\
\hline Low knowledge & 19 & $32.8 \%$ & 15 & $23.4 \%$ & 0.25 \\
\hline \multicolumn{6}{|l|}{ Incentives } \\
\hline High knowledge & 25 & $42.3 \%$ & 39 & $60.0 \%$ & \\
\hline Low knowledge & 34 & $57.7 \%$ & 26 & $40.0 \%$ & 0.05 \\
\hline \multicolumn{6}{|l|}{ Legal Issues } \\
\hline High knowledge & 20 & $33.9 \%$ & 33 & $50.8 \%$ & \\
\hline Low knowledge & 39 & $66.1 \%$ & 32 & $49.2 \%$ & 0.04 \\
\hline \multicolumn{6}{|l|}{ Human Resources } \\
\hline High knowledge & 24 & $40.7 \%$ & 45 & $69.2 \%$ & \\
\hline Low knowledge & 35 & $59.3 \%$ & 20 & $30.8 \%$ & 0.002 \\
\hline \multicolumn{6}{|l|}{ Associateship Practice } \\
\hline High knowledge & 31 & $53.4 \%$ & 49 & $75.4 \%$ & \\
\hline Low knowledge & 27 & $46.6 \%$ & 16 & $24.6 \%$ & 0.01 \\
\hline \multicolumn{6}{|l|}{ Loan Procurement } \\
\hline High knowledge & 23 & $39.0 \%$ & 47 & $71.2 \%$ & \\
\hline Low knowledge & 36 & $61.0 \%$ & 19 & $28.8 \%$ & 0.001 \\
\hline \multicolumn{6}{|l|}{ Marketing } \\
\hline High knowledge & 21 & $35.6 \%$ & 45 & $69.2 \%$ & \\
\hline Low knowledge & 38 & $64.4 \%$ & 20 & $30.8 \%$ & 0.002 \\
\hline \multicolumn{6}{|l|}{ Insurance } \\
\hline High knowledge & 32 & $54.2 \%$ & 50 & $78.1 \%$ & \\
\hline Low knowledge & 27 & $45.8 \%$ & 14 & $21.9 \%$ & 0.005 \\
\hline \multicolumn{6}{|l|}{ Accounting } \\
\hline High knowledge & 39 & $66.1 \%$ & 37 & $56.9 \%$ & \\
\hline Low knowledge & 20 & $33.9 \%$ & 28 & $43.1 \%$ & 0.01 \\
\hline \multicolumn{6}{|l|}{ Retirement } \\
\hline High knowledge & 26 & $44.1 \%$ & 44 & $67.7 \%$ & \\
\hline Low knowledge & 33 & $55.9 \%$ & 21 & $32.3 \%$ & 0.008 \\
\hline
\end{tabular}

Note: The number of responses to individual items varied. Comparisons were carried out using Cochran-Mantal-Haenszel chi-square test of association between practice experience groups. Significance set at $\mathrm{P}<.05$. 
Table 3. Respondents' perception of knowledge-experience in practice management topics at the present time as compared to perception of preparedness at graduation $(n=133)$, by number and percentage of total respondents to each question by level of perceived preparedness

\begin{tabular}{|c|c|c|c|c|c|}
\hline \multirow[b]{2}{*}{ Topic } & \multicolumn{2}{|c|}{ Prepared at Graduation } & \multicolumn{2}{|c|}{ Unprepared at Graduation } & \multirow[b]{2}{*}{ P-Value } \\
\hline & Number & Percentage & Number & Percentage & \\
\hline \multicolumn{6}{|l|}{ Purchasing } \\
\hline High knowledge & 17 & $89.5 \%$ & 65 & $58.0 \%$ & \\
\hline Low knowledge & 2 & $10.5 \%$ & 47 & $42.0 \%$ & 0.008 \\
\hline \multicolumn{6}{|l|}{ Case Presentation } \\
\hline High knowledge & 16 & $88.9 \%$ & 78 & $70.3 \%$ & \\
\hline Low knowledge & 2 & $11.1 \%$ & 33 & $29.7 \%$ & 0.09 \\
\hline \multicolumn{6}{|l|}{ Incentives } \\
\hline High knowledge & 14 & $73.7 \%$ & 55 & $49.1 \%$ & \\
\hline Low knowledge & 5 & $26.3 \%$ & 57 & $50.9 \%$ & 0.04 \\
\hline \multicolumn{6}{|l|}{ Legal Issues } \\
\hline High knowledge & 14 & $73.7 \%$ & 43 & $38.4 \%$ & \\
\hline Low knowledge & 5 & $26.3 \%$ & 69 & $61.6 \%$ & 0.004 \\
\hline \multicolumn{6}{|l|}{ Human Resources } \\
\hline High knowledge & 14 & $73.7 \%$ & 60 & $53.6 \%$ & \\
\hline Low knowledge & 5 & $26.3 \%$ & 52 & $46.4 \%$ & 0.10 \\
\hline \multicolumn{6}{|l|}{ Associateship Practice } \\
\hline High knowledge & 13 & $68.4 \%$ & 71 & $64.0 \%$ & \\
\hline Low knowledge & 6 & $31.6 \%$ & 40 & $36.0 \%$ & 0.70 \\
\hline \multicolumn{6}{|l|}{ Loan Procurement } \\
\hline High knowledge & 14 & $73.7 \%$ & 62 & $55.4 \%$ & \\
\hline Low knowledge & 5 & $26.3 \%$ & 50 & $44.6 \%$ & 0.13 \\
\hline \multicolumn{6}{|l|}{ Marketing } \\
\hline High knowledge & 13 & $68.4 \%$ & 59 & $52.7 \%$ & \\
\hline Low knowledge & 6 & $31.6 \%$ & 53 & $47.3 \%$ & 0.20 \\
\hline \multicolumn{6}{|l|}{ Insurance } \\
\hline High knowledge & 15 & $78.9 \%$ & 73 & $65.8 \%$ & \\
\hline Low knowledge & 4 & $21.1 \%$ & 38 & $34.2 \%$ & 0.25 \\
\hline \multicolumn{6}{|l|}{ Accounting } \\
\hline High knowledge & 14 & $73.7 \%$ & 48 & $42.9 \%$ & \\
\hline Low knowledge & 5 & $26.3 \%$ & 64 & $57.1 \%$ & 0.01 \\
\hline \multicolumn{6}{|l|}{ Retirement } \\
\hline High knowledge & 14 & $73.7 \%$ & 62 & $55.4 \%$ & \\
\hline Low knowledge & 5 & $26.3 \%$ & 50 & $44.6 \%$ & 0.13 \\
\hline
\end{tabular}

high knowledge/experience of accounting, purchasing, incentives/motivational tools, and experience with legal issues.

In addition to providing information on alumni perceptions of preparedness in practice management topics, it was the goal of this study to gain a better understanding of how these perceptions may impact practice characteristics. To examine these possible impacts, we evaluated correlations between practice management knowledge/experience and personal income and practice income using chi-square analysis. The level of a respondent's reported personal income $\geq \$ 200,000$ was significantly associated with having a high level of present knowledge/experience of accounting, purchasing (overhead), and $401 \mathrm{~K} /$ retirement fund planning (Table 4). Not unexpectedly, a higher personal income was associated with the respondent's age, increasing number of years at a particular practice, and having either an associate or ownership position within the dental practice. 
Table 4. Association between respondents' personal income and perception of knowledge/experience in practice management topics and practice characteristics $(n=133)$, by number and percentage of total respondents to each question by personal income level

\begin{tabular}{|c|c|c|c|c|c|}
\hline \multicolumn{3}{|c|}{ Personal Income $<\$ 200,000$} & \multicolumn{2}{|c|}{ Personal Income $\geq \$ 200,000$} & \multirow[b]{2}{*}{ P-Value } \\
\hline Topic/Practice Characteristic & Number & Percentage & Number & Percentage & \\
\hline \multicolumn{6}{|l|}{ Purchasing } \\
\hline High knowledge & 45 & $51.1 \%$ & 34 & $85.0 \%$ & \\
\hline Low knowledge & 43 & $48.9 \%$ & 6 & $15.0 \%$ & 0.003 \\
\hline \multicolumn{6}{|l|}{ Accounting } \\
\hline High knowledge & 31 & $35.2 \%$ & 30 & $75.0 \%$ & \\
\hline Low knowledge & 57 & $64.8 \%$ & 10 & $25.0 \%$ & 0.0001 \\
\hline \multicolumn{6}{|l|}{ Associateships } \\
\hline High knowledge & 55 & $62.5 \%$ & 27 & $67.5 \%$ & \\
\hline Low knowledge & 33 & $37.5 \%$ & 13 & $32.5 \%$ & 0.584 \\
\hline \multicolumn{6}{|l|}{ 401K/Retirement Plans } \\
\hline High knowledge & 46 & $52.3 \%$ & 28 & $70.0 \%$ & \\
\hline Low knowledge & 42 & $47.7 \%$ & 12 & $30.0 \%$ & 0.051 \\
\hline \multicolumn{6}{|l|}{ Loan Procurement } \\
\hline High knowledge & 44 & $50.0 \%$ & 30 & $75.0 \%$ & \\
\hline Low knowledge & 44 & $50.0 \%$ & 10 & $25.0 \%$ & 0.0082 \\
\hline \multicolumn{6}{|l|}{ Work Status ${ }^{+}$} \\
\hline Associate & 41 & $46.0 \%$ & 2 & $5.0 \%$ & \\
\hline Co-owner & 10 & $25.6 \%$ & 12 & $30.0 \%$ & \\
\hline Owner & 25 & $28.1 \%$ & 26 & $65.0 \%$ & 0.0001 \\
\hline \multicolumn{6}{|l|}{ Age } \\
\hline $20-29$ & 18 & $21.2 \%$ & 2 & $5.0 \%$ & \\
\hline $30-39$ & 61 & $71.8 \%$ & 33 & $82.5 \%$ & \\
\hline 40 or over & 6 & $7.0 \%$ & 5 & $12.5 \%$ & 0.049 \\
\hline \multicolumn{6}{|c|}{ Number of years at same practice } \\
\hline $0-2$ & 33 & $37.1 \%$ & 5 & $12.5 \%$ & \\
\hline $3-4$ & 35 & $39.3 \%$ & 10 & $25.0 \%$ & \\
\hline $5-6$ & 12 & $13.5 \%$ & 11 & $27.5 \%$ & \\
\hline 7 or more & 9 & $10.1 \%$ & 14 & $35.0 \%$ & 0.002 \\
\hline \multicolumn{6}{|l|}{ Number of employees } \\
\hline $0-4$ & 27 & $30.7 \%$ & 5 & $12.8 \%$ & \\
\hline 5 or 6 & 8 & $9.1 \%$ & 7 & $17.9 \%$ & \\
\hline 7 or more & 53 & $60.2 \%$ & 27 & $69.3 \%$ & 0.06 \\
\hline
\end{tabular}

${ }^{+}$Work Status categories shown in this table do not include Faculty and Other, so percentages total less than 100 percent.

Practice income was significantly associated with having a high knowledge of case presentation, incentives/motivational tools, purchasing (overhead), and human resources (Table 5). Practice characteristics such as the number of employees (many alumni were in practices that employed eight or more individuals) and the number of operatories were highly correlated with practice income levels. Age was not associated with practice income. Interestingly, a respondent's perception of preparedness at graduation was not statistically significant with practice income $(\mathrm{P}<0.10)$ nor personal income $(\mathrm{P}<0.07)$.
Figure 3 shows the length of time that it took for respondents to achieve confidence in their practice management skills. Forty-six percent of the respondents indicated that within a five-year period they had achieved a level of mastery at which they were confident in their skills. Nearly 25 percent of the respondents indicated that they required six to ten years to achieve a level of proficiency that they were comfortable with, while the remainder indicated they required greater than ten years or still required greater knowledge in running a practice. 
Table 5. Association between respondents' practice income and perception of knowledge/experience in practice management topics and practice characteristics $(n=133)$, by number and percentage of total respondents to each question by practice income level

\begin{tabular}{|c|c|c|c|c|c|}
\hline \multirow[b]{2}{*}{ Topic/Practice Characteristic } & \multicolumn{2}{|c|}{ Practice Income $<\$ 300,000$} & \multicolumn{2}{|c|}{ Practice Income $\geq \$ 300,000$} & \multirow[b]{2}{*}{ P-Value } \\
\hline & Number & Percentage & Number & Percentage & \\
\hline \multicolumn{6}{|l|}{ Purchasing } \\
\hline High knowledge & 18 & $75.0 \%$ & 81 & $92.0 \%$ & \\
\hline Low knowledge & 6 & $25.0 \%$ & 7 & $8.0 \%$ & 0.020 \\
\hline \multicolumn{6}{|l|}{ Case Presentation } \\
\hline High knowledge & 2 & $8.7 \%$ & 24 & $27.6 \%$ & \\
\hline Low knowledge & 21 & $91.3 \%$ & 63 & $72.4 \%$ & 0.05 \\
\hline \multicolumn{6}{|l|}{ Incentives } \\
\hline High knowledge & 7 & $29.2 \%$ & 45 & $51.1 \%$ & \\
\hline Low knowledge & 17 & $70.8 \%$ & 43 & $48.9 \%$ & 0.051 \\
\hline \multicolumn{6}{|l|}{ Legal Issues } \\
\hline High knowledge & 19 & $79.2 \%$ & 83 & $94.3 \%$ & \\
\hline Low knowledge & 5 & $20.8 \%$ & 5 & $5.7 \%$ & 0.021 \\
\hline \multicolumn{6}{|l|}{ Human Resources } \\
\hline High knowledge & 5 & $71.4 \%$ & 41 & $46.6 \%$ & \\
\hline Low knowledge & 2 & $28.6 \%$ & 47 & $53.4 \%$ & 0.023 \\
\hline \multicolumn{6}{|l|}{ Work Status } \\
\hline Associate & 4 & $13.3 \%$ & 32 & $36.4 \%$ & \\
\hline Co-owner & 6 & $20.0 \%$ & 19 & $21.6 \%$ & \\
\hline Owner & 14 & $46.7 \%$ & 34 & $38.6 \%$ & \\
\hline Faculty/Other & 6 & $20.0 \%$ & 3 & $3.4 \%$ & 0.05 \\
\hline \multicolumn{6}{|l|}{ Number of Employees } \\
\hline $0-4$ & 12 & $50.0 \%$ & 14 & $16.1 \%$ & \\
\hline 5 or 6 & 3 & $12.5 \%$ & 9 & $10.3 \%$ & \\
\hline 7 or more & 9 & $37.5 \%$ & 64 & $73.6 \%$ & 0.001 \\
\hline \multicolumn{6}{|l|}{ Number of Operatories } \\
\hline $1-4$ & 13 & $56.6 \%$ & 17 & $19.3 \%$ & \\
\hline 5 or 6 & 5 & $21.7 \%$ & 31 & $35.2 \%$ & \\
\hline 7 or more & 5 & $21.7 \%$ & 40 & $45.5 \%$ & 0.003 \\
\hline
\end{tabular}

To determine the sources of practice management information, graduates were asked where they acquired their practice management skills. The respondents indicated that they had acquired most of their expertise in practice management from mentors, CE courses, or while in dental school (Figure 4). Overall, consultants and office managers appeared to provide the least input for dentists achieving perceived competence in running dental businesses. Of the 15 percent of alumni who indicated they felt prepared at graduation in practice management topics, there was a significant relationship between having dental school practice management courses as a source for practice management information $(\mathrm{P}<0.01)$ and feeling prepared at graduation. Interest- ingly, one-third of the respondents did not indicate dental school practice management courses as a source of information, yet indicated feeling prepared in practice management at graduation.

\section{Discussion}

The purpose of this study was to determine the knowledge and perceptions of University of Michigan School of Dentistry graduates in the area of practice management. The results suggest a need to increase the number of educational opportunities in the dental curriculum to address a perceived need by graduates in this area. Nearly 85 percent of responding gradu- 


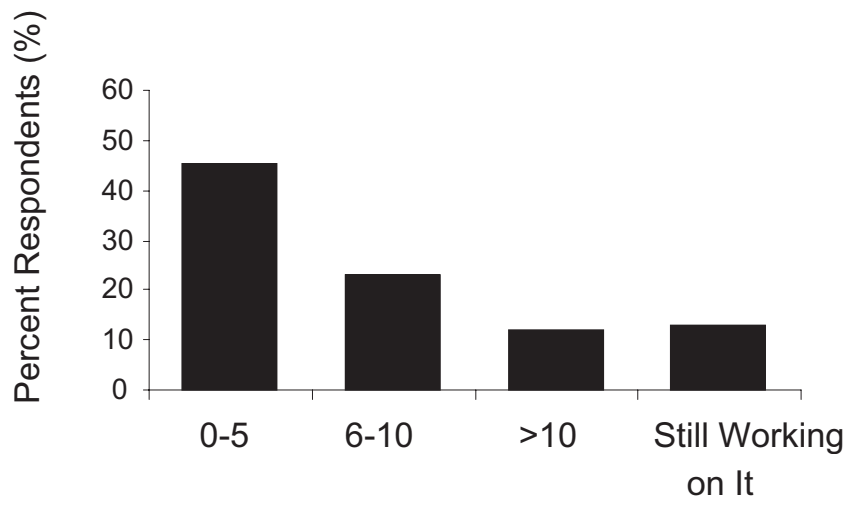

Figure 3. Years respondents reported needing to feel comfortable in their practice management skills after graduation

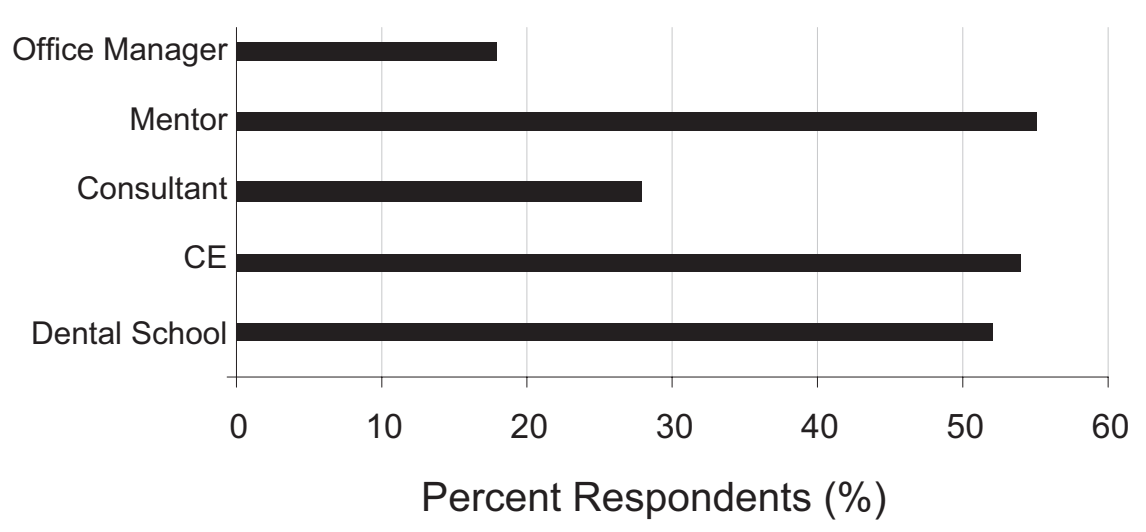

Figure 4. Sources of learning practice management skills reported by respondents

ates indicated that they felt unprepared at graduation in practice management. This finding is higher than that from the 2008 national survey of dental school seniors, in which 66.8 percent indicated a perception of inadequate preparedness in practice administration. ${ }^{11}$ The disparity between curriculum and dental students' expectations in practice management is not unique. ${ }^{12}$

One possible reason that dental graduates feel ill prepared in business skills is that most college undergraduates focus on the biological sciences as a proven track for gaining admission into dental school at the expense of developing knowledge in business. ${ }^{13-15}$ The consequence is that the burden of teaching these skills falls almost exclusively on dental schools at a time when there is increasing competition for space within the curriculum. Suggestions for increasing business training for dental students include encouraging undergraduates to take business or human behaviors minors as part of their predental track or allowing time within the dental curriculum for dual degrees. This may require a shift in dental schools' perceptions about what constitutes an "ideal" predental track or building partnerships with business schools.

\section{Practice Management Knowledge}

Although our results echo previous studies that indicate dental students expect more practice 
management information and experiences, of note is the finding that the level of experience/knowledge of practice management is significantly associated with both a high level of knowledge in key practice management topics and personal and practice incomes. Those respondents who indicated a high level of knowledge/experience with practice management topics (e.g., accounting, purchasing, and $401 \mathrm{~K} /$ retirement fund planning) reported a personal income $>\$ 200,000(\mathrm{P}<0.05)$. Furthermore, a higher personal income was associated with age of respondent, increasing number of years at a particular practice, and having either an associate or ownership position within the dental practice. Similarly, a high knowledge/experience of purchasing (overhead costs), accounting, legal issues, and staff-related practice management was related to a high practice income. Our data support a previous study that found knowledge of legal issues related to associateships, practice purchases, and choosing the correct business entity is crucial to practice income. ${ }^{16}$

Preparedness at graduation was not significantly correlated with a respondent's current personal or practice income. This suggests knowledge and/ or skill acquisition in the workforce must be rapidly acquired. However, nearly one-third of those who indicated feeling prepared at graduation were in the top level of personal and practice income. There may be other personality factors that play a part in the achievement of these areas. While dental practice management can be learned through experience in running or working in a private practice, this approach is time-consuming and can result in unnecessary and costly mistakes. Roughly 25 percent of the respondents noted that they were still working on feeling comfortable with practice management topics, which in turn could affect both their practice and personal income potential.

\section{Dental Practice Characteristics}

Additional analyses were performed to determine if a correlation existed between years in practice, number of operatories, and personal income. Not surprisingly, years in practice were associated with increased levels of personal income (Table 2). However, the number of operatories were associated with practice income but not with personal income. It is unclear why these discrepancies exist, particularly when the majority of the practitioners reported being owners or co-owners. One possibility that may ac- count for these observations was whether the practice was being built and revenue was being reinvested into the enterprise or the practice has reached a level of maturity in which revenue was being withdrawn. While a higher personal income was associated with age of respondent, increasing number of years at a particular practice, having either an associate or ownership position within the dental practice, and factors such as age could not be controlled for due to the small number of observations.

We found it intriguing that the majority of our respondents reported they had worked at a particular practice for less than four years and 45.5 percent had been in practice for less than five years, while at the same time 78.6 percent reported practice incomes in excess of $\$ 300,000$. As was pointed out by one of the reviewers of this work, the sample size is small and may have introduced significant bias in regards to the stated income. At an average overhead of 67 to 70 percent, the $\$ 300,000$ net practices would all have to have earned over a million dollars per year. With the majority of respondents between the ages of thirty and thirty-nine, they would have been producing and earning numbers in the top 10 percent of all dentists in the United States. ${ }^{17}$

\section{Source of Practice Management Information}

Interestingly, of the 15 percent of respondents who indicated a sense of preparedness in practice management topics at graduation, nearly one-third did not indicate dental school as the source of information. It has been suggested that even when instructional events in practice management are provided in the dental curriculum, not all students take advantage of the opportunities. It is unclear why dental students fail to participate in instructional events provided in this area of their education. ${ }^{18-20}$ Possibly, few dental students see the relevance of practice management education during their years in dental school as they are focused on gaining skills needed to adequately and safely treat patients and many aspects of practice management are provided by the institution during their clinical education. Yet, as they enter the workforce and gain clinical expertise in these areas, perhaps graduates begin to understand that there are other areas of practice that require development.

The open-ended statements correlate with the overall findings of this assessment. Most respondents expressed a desire for greater experiences in practice 
management courses - specifically, associateships, insurance, finances of small business management, and accounting. A common theme was that while dental school courses covered the basics of practice management, the number and type of classes did not prepare them for practice. The most striking finding of this study was that graduates felt they were not prepared to enter the workplace with the level of knowledge they had acquired in dental school. Perhaps this is because they are aware they need to rapidly achieve competence in the business aspects of dentistry to succeed in a private practice setting. ${ }^{3,21}$ How these skills should be acquired and what the appropriate emphasis should be for schools in teaching these skills, while at the same time educating students in the art and science of dentistry, remain areas of conjecture. An approach no longer favored in most academic settings is that practice management skills should be learned on the job. Yet the results from this survey indicate that interventions may be needed to increase a graduating dentist's knowledge of practice management skills and close the gap between knowledge and its application in the workplace.

A possibility worth considering is whether dental graduates evaluate their skills development in practice management by criteria that are different from skills associated with the delivery of dental care. When one evaluates competence in restorative dentistry, periodontics, or endodontics, there are defined criteria established in dental school for what is clinically acceptable. No such criteria are defined in practice management that can easily be evaluated by the practitioner. For that matter, little feedback is provided to dental students that tracks skills growth in practice management skills in the clinic or practice setting. Thus, it is possible that graduates evaluate their business skills by different criteria than they use to evaluate their proficiency in chairside dentistry. If this is a possibility, it will be critical to incorporate into future study designs intended to determine skill attainment in practice management an independent measure of skills gained relative to skills gained in other areas of dental practice.

The respondents in our study made suggestions for how dental education can be changed to help prepare graduates in practice management topics. One said that "practice management should be taught for more than the D4 class ... should start integrating business models into curriculum during the D2 or D3 year"; another encouraged the use of "guest speakers or collaboration with business school cur- riculum." Sadly, none of the suggestions were novel or untried (e.g., supplemental resources, electives, or dual degree programs). Thus, how to achieve these goals within most existing curricula remains unclear.

It was intriguing to note that while the respondents reported differences between their perceived knowledge at graduation and after they had entered the workforce, the majority reported that they learned at least as much of their practice management skills in dental school as from any other reported source. Unfortunately, the basis for these perceptions is not clear and will require further study. However, the open-ended responses may clarify their expectations for practice management courses. Many comments reflected the feeling expressed by this respondent: "We learned how to be good dentists in school—not enough time to learn management and business." Another commented that "no number of courses in dental school can prepare you for running a practice. So much of the information becomes meaningful after you've been in practice." "We had great practice management classes," said another, "but my mentor taught me everything about running a practice: ... office staff, accounting, insurance, front desk, scheduling, pay/receivable." Many reflected that, as in learning any technical skill, dental schools provide students with basic information, but as one said, "you need 'practice' at practice management because you need to deal with all kinds of patients, all kinds of treatments, and feel comfortable with your technical dental abilities as well." Another comment echoed that theme: "I was as prepared as I think you can be coming out of school. It's hard to concentrate on becoming a good dentist and trying to juggle practice management. I learned a lot of what I know from the dentist I worked for out of school." The common perception that much of practice management skills/ experiences simply cannot be learned while in dental school has been noted before. ${ }^{22}$

\section{Study Limitations}

While this study suggests that dental graduates need additional expertise in the business of dentistry, it has a number of limitations. Importantly, only a 27 percent response rate to the survey was achieved. Although low response rates have occurred in other health care provider surveys, ${ }^{23}$ our rate is lower than those reported in similar surveys. While a cover letter and return envelope were included with the survey, the low response rate was likely attributable to the 
fact that no efforts were made to follow up with nonrespondents. It is unknown why most recipients of the request did not respond or why those who did felt compelled do so. Thus, the biases of those who responded may have skewed the results in favor of those who felt less prepared in their practice management/business skills. Future studies should place greater emphasis in the study design to address potential response bias. It also is not known how representative these results are for other institutions. However, the most recent American Dental Education Association annual survey of dental school seniors, ${ }^{11}$ in which nearly 67 percent reported feeling inadequately prepared in practice management, indicates our results may be comparable to those from other dental schools.

Another limitation to this study was the depth of information collected on dental practice characteristics and perceived deficiency of practice management courses within the current dental curriculum. For example, while it was asked how many employees were in a practice, a more meaningful question would have been how many full-time equivalents are in the practice. It is also relevant that the incomes reported by respondents were high compared to national averages. ${ }^{11}$ Data collection about benchmark categories of production per staff member, production of doctor per hour, number of new patients, and overhead (marketing, staff, facility, lab, dental supplies, and office supplies) would have been beneficial and would have provided greater confidence in the reported profitability and productivity. Further assessment should be done to better understand the mechanisms to increase dental graduates' perceptions of preparedness in practice management topics. Questions should address perceived deficiencies within the dental curriculum such as specific practice management courses or mechanisms to gain missing knowledge while in dental school. Little information was gathered on personal and professional satisfaction, nor did the study address issues related to practice philosophy. In addition, questions should address the most important lessons respondents would like to pass on to new graduates. Also, it would be beneficial to determine the most effective mechanisms to bridge the knowledge gap between what is known at graduation and what is learned once in practice, as well as understanding the value of consultants and the most valuable lessons learned in CE classes. Finally, instead of the current model of collecting data in cross-sectional surveys, prospective study designs might further elucidate how graduates determine the degree to which they are lacking practice management skill sets and how they gain these skills over time.

\section{Conclusions}

Together, these results and respondents' comments suggest that a closer examination of practice management courses and their application to real life is warranted. The majority of our respondents reported a need to increase the number of learning opportunities within the dental curriculum, yet many realized that much of what is learned in this area cannot be taught in a dental school setting for many reasons. Clearly, the importance of mastering practice management principles is essential to a dentist's success in practice. The rapidly changing economic environment and its impact on the practice of dentistry suggest that dental graduates need more business knowledge in marketing, loan procurement, and accounting than ever before. Preparing graduates to operate a dental practice using sound business principles is vital to their success.

\section{REFERENCES}

1. Barron EG, Shirley WL, Waldrep AC. A realistic approach to locating dental practices. J Am Dent Assoc 1984;109: 903-8.

2. Van Blarcom C. Prosthodontics: clinical practice-third-party relations — review of the literature. J Prosthet Dent 1990;64: 293-310.

3. Chambers DW. The continuing education business. J Dent Educ 1992;56(10):672-9.

4. Atherton GJ, McCaul JA, Williams SA. Medical emergencies in general dental practice in Great Britain. Part 3: perceptions of training and competence of GDPs in their management. Br Dent J 1999;186:234-7.

5. Rafeek RN, Marchan SM, Naidu RS, Carrotte PV. Perceived competency at graduation among dental alumni of the University of the West Indies. J Dent Educ 2004; 68(1):81-8.

6. Krastl G, Filippi A, Weiger R. German general dentists knowledge of dental trauma. Dent Traumatol 2009;25: 88-91.

7. Bertolami CN. Creating the dental school faculty of the future: a guide for the perplexed. J Dent Educ 2007;71(10): 1267-80.

8. Cardall WR, Rowan RC, Bay C. Dental education from the students' perspective: curriculum and climate. J Dent Educ 2008;72(5):600-9.

9. Comer RW, Callan RS, Blalock JS, Turner JE, Trombly RM. Small business needs assessment: a comparison of dental educators' responses with SBDC survey results. J Dent Educ 2001;65(9):866-73. 
10. Paquette JM, Sheets CG. The second "DDS" degree: a formula for practice success. J Am Dent Assoc 2004;135: 1321-5.

11. Okwuje I, Anderson E, Valachovic RW. Annual ADEA survey of dental school seniors: 2008 graduating class. J Dent Educ 2009;73(8):1009-32.

12. Houlberg BJ. Dental residents' perceptions of practice and patient management training during postgraduate education. J Dent Educ 2008;72(6):643-52.

13. Mentasti LE, Thibodeau EA. Predental enrichment activities of U.S. colleges and universities. J Dent Educ 2005; 69(8):890-5.

14. Mentasti LE, Thibodeau EA. Nonacademic characteristics of dental school applicants. J Dent Educ 2006;70(10): 1043-50.

15. Markel G, Woolfolk M, Inglehart MR. Feeding the pipeline: academic skills training for predental students. J Dent Educ 2008;72(6):653-61.

16. Barrabee S, Kowalski M. The legal business of dentistry. J Calif Dent Assoc 2009;37:621-9.
17. Occupational employment and wages. Washington, DC: U.S. Bureau of Labor Statistics, 2008.

18. Pickworth GE, Snyman WD, White JG, Beukes SJ. The dilemma of student attendance of learning opportunities. J S Afr Dent Assoc 2005;60:73-7.

19. Schönwetter DJ, Lavigne S, Mazurat R, Nazarko O. Students' perceptions of effective classroom and clinical teaching in dental and dental hygiene education. J Dent Educ 2006;70(6):624-35.

20. Reynolds PA, Mason R, Eaton KA. Remember the days in the old school yard: from lectures to online learning. Br Dent J 2008;204:447-51.

21. Klein G. Time to shift focus to business and management skills. Trends Tech Contemp Dent Lab 1991;8:9-13.

22. Nadershahi NA, Nielsen DB. Educating the practice-ready dentist. J Calif Dent Assoc 2005;33:801-4.

23. Coats MJ, Straja SR, Wiser G, Heckman H, Saavedra W, Tuncay OC. Defining characteristics of financially successful orthodontists. Am J Orthod Dentofacial Orthop 2000;118:18-23. 